\title{
How well can online GPS PPP post-processing services be used to establish geodetic survey control networks?
}

\author{
R. Ebner, W. E. Featherstone
}

\begin{abstract}
Establishing geodetic control networks for subsequent surveys can be a costly business, even when using GPS. Multiple stations should be occupied simultaneously and post-processed with scientific software. However, the free availability of online GPS precise point positioning (PPP) post-processing services offer the opportunity to establish a whole geodetic control network with just one dualfrequency receiver and one field crew. To test this idea, we compared coordinates from a moderatesized ( $\sim 550 \mathrm{~km}$ by $\sim 440 \mathrm{~km}$ ) geodetic network of 46 points over part of south-western Western Australia, which were processed both with the Bernese v5 scientific software and with the CSRS (Canadian Spatial Reference System) PPP free online service. After rejection of five stations where the antenna type was not recognised by CSRS, the PPP solutions agreed on average with the Bernese solutions to $3.3 \mathrm{~mm}$ in east, $4.8 \mathrm{~mm}$ in north and $11.8 \mathrm{~mm}$ in height. The average standard deviations of the Bernese solutions were $1.0 \mathrm{~mm}$ in east, $1.2 \mathrm{~mm}$ in north and $6.2 \mathrm{~mm}$ in height, whereas for CSRS they were $3.9 \mathrm{~mm}$ in east, $1.9 \mathrm{~mm}$ in north and $7.8 \mathrm{~mm}$ in height, reflecting the inherently lower precision of PPP. However, at the $99 \%$ confidence level, only one CSRS solution was statistically different to the Bernese solution in the north component, due to a data interruption at that site. Nevertheless, PPP can still be used to establish geodetic survey control, albeit with a slightly lower quality because of the larger standard deviations. This approach may be of particular benefit in developing countries or remote regions, where geodetic infrastructure is sparse and would not normally be established without this approach.
\end{abstract}

Keywords. Geodetic survey control, precise point positioning (PPP), CSRS, Bernese.

\section{Introduction}

GPS has now become a preferred tool for establishing or upgrading geodetic survey control networks on regional, national and continental scales (e.g., Bock et al. 1985, Stewart et al. 1997). Conventionally, these networks are established using many (ideally of the same type) geodetic-quality dualfrequency carrier-phase GPS receivers and antennas, where multiple sites (ideally all) should be occupied simultaneously. This network-based approach makes the task rather costly in terms of not only equipment and personnel, but also careful pre-planning and in- field logistical considerations. It also requires postprocessing and analysis of the data using scientific software packages, which are not generally too accessible to inexperienced users.

On the other hand, the GPS precise point positioning (PPP) technique requires just one dual-frequency GPS receiver, and these observations are then postprocessed using precise satellite orbits and clock parameters from the International GNSS Service (IGS; Moore and Neilan 2005); see, e.g., Zumberge et al. (1997), Kouba and Héroux (2001) and Cai and Gao (2007). This opens up the possibility to establish a geodetic survey control network using only a single GPS receiver and only a single field crew (cf. Featherstone and Dent 2002). This PPP-based approach significantly reduces the equipment and personnel costs, pre-planning and logistics compared to 'conventional' GPS-network-based approaches. It also lessens the need to learn to use scientific GPS processing packages properly. As such, it offers an attractive alternative to establish a geodetic survey control network, notably in developing countries or remote regions.

We acknowledge that PPP is inherently less accurate than network-processed relative GPS (e.g., because of its inability to fix carrier-phase integer ambiguities; cf. Ge et al. (2007)), but this lower accuracy may prove to be acceptable when balanced against the costs of a simultaneous network occupation. Essentially, PPP could provide useable geodetic survey control points in areas where they would otherwise not exist. For instance, a single survey crew could be deployed to establish a geodetic survey control network across a large area, rather than the complicated logistics and communications needed to organise multiple survey crews to occupy stations simultaneously. It is also attractive to use in remote regions, where access to communications infrastructure may be limited.

In this case-study, we investigate what accuracy could be expected from our proposed PPP-only approach to establishing a geodetic survey control network. We compared a network GPS solution across a moderate-sized $(\sim 550 \mathrm{~km}$ by $\sim 440 \mathrm{~km})$ part of south-western Western Australia (Featherstone et al. 2004) processed by $\mathrm{Hu}$ (2007) with the Bernese v5 scientific software (Hugentobler et al. 2006) with PPP solutions for the same raw data processed with Natural Resources Canada's CSRS (Canadian Spatial Reference System) free online service (http://ess .nrcan.gc.ca/2002_2006/gnd/csrs_e.php). This shows 
that the approach is feasible, but some auxiliary considerations arise, as follows.

\section{Data \& methods}

The GPS data used in this test were collected as part of a campaign-based attempt to quantify any contemporary surface deformation associated with intra-plate seismic activity in the south-west seismic zone (SWSZ) of Western Australia (Featherstone et al. 2004, Dentith and Featherstone 2003); see Figure 1 and 2 .

The data were collected during May 2002 using a variety of GPS receiver and antenna types (Trimble, Ashtech and Leica), and occupation epochs (4-21 days), allowing us to get an indication of the occupation time required to get a certain precision (cf. Ghoddousi-Fard and Dare 2005). These data were originally processed by Dawson (2002), then reprocessed by $\mathrm{Hu}$ (2007) using the Bernese v5 scientific software in network mode, including the nearest IGS sites in Australia (Figure 2), to give coordinates in the International Terrestrial Reference Frame 2000 (ITRF2000) (Altamimi et al. 2002) at the mean epoch of the observations $(02: 135)$.

Of the 48 sites occupied in 2002, two sites (SZ23 and SZ36) had to be excluded from the Bernese processing because of poor data quality (cf. Featherstone et al. 2004). The remaining 46 sites for which $\mathrm{Hu}$ (2007) gives results were used here as 'truth' as would normally be determined from a 'conventional' GPS network occupation, and then compared with the CSRS PPP solutions for the same points as if they had been occupied sequentially by a single survey crew. It should be noted that the same data are used twice in these experiments, which will mask the effects of systematic errors, e.g., multipath will affect the Bernese and CSRS PPP solutions similarly, and centring errors over the ground monuments will vanish in the comparisons.

Figure 3 shows the magnitude of the standard deviations of the 'true' coordinates derived from internally propagated errors in the Bernese processing as an indication of the data and solution quality. There is good consistency among the standard deviations for each of the 46 stations. The heights are approximately four times worse than the horizontal positions, which is consistent with expectation. However, the standard deviations of the latitudes are consistently $\sim 20 \%$ worse than the longitudes. This is caused by the GPS satellite constellation when using fixed ambiguities, where the East-West positioning precision is generally slightly better than the NorthSouth positioning precision (e.g., Wang et al. 2002).

The RINEX (receiver-independent exchange) format (http://www.aiub-download.unibe.ch/rinex/rinex300 .pdf) files from the 2002 SWSZ campaign were uploaded to the CSRS service and the resulting

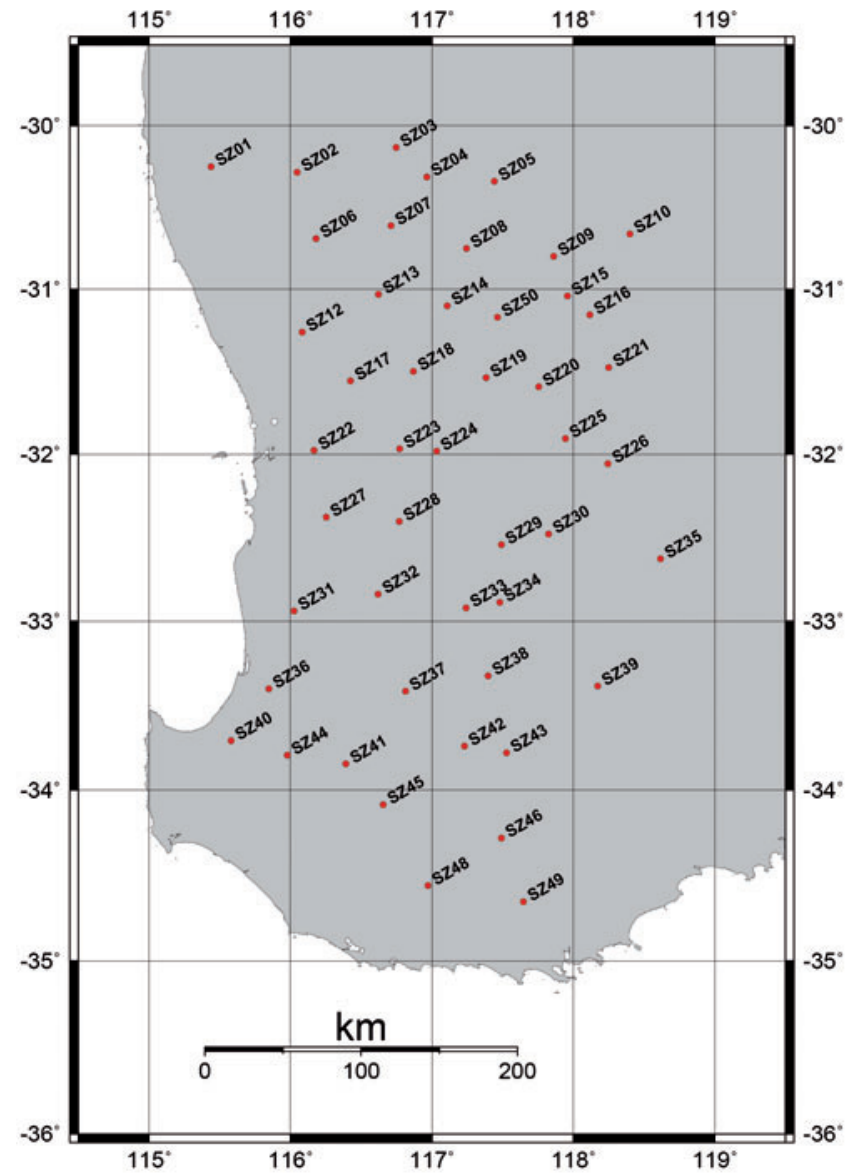

Figure 1: The 48-point SWSZ geodetic control network (from Dawson 2002) [Mercator projection].

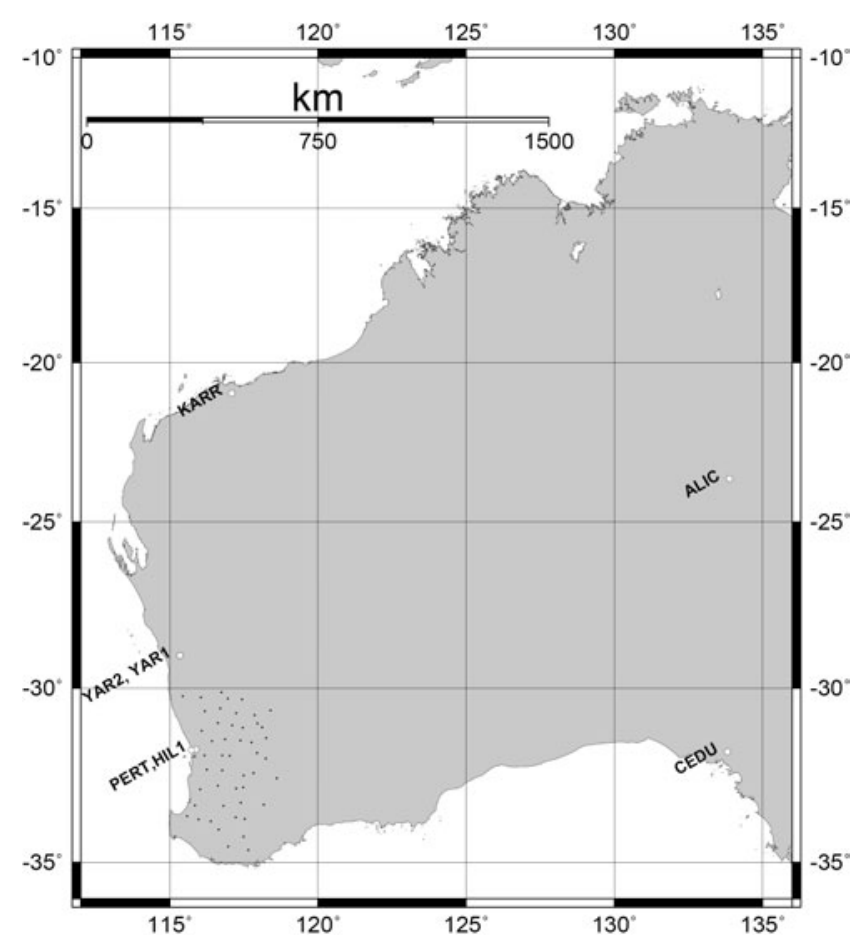

Figure 2: Distribution of the IGS stations used (Alice Springs (ALIC), Karratha (KARR), Ceduna (CEDU), Yaragadee (YAR2), Hilarys (HIL1) and Perth (PERT)) in the Bernese processing in relation to SWSZ geodetic control network; cf. Figure 1 (from Dawson 2002) [Mercator projection]. 


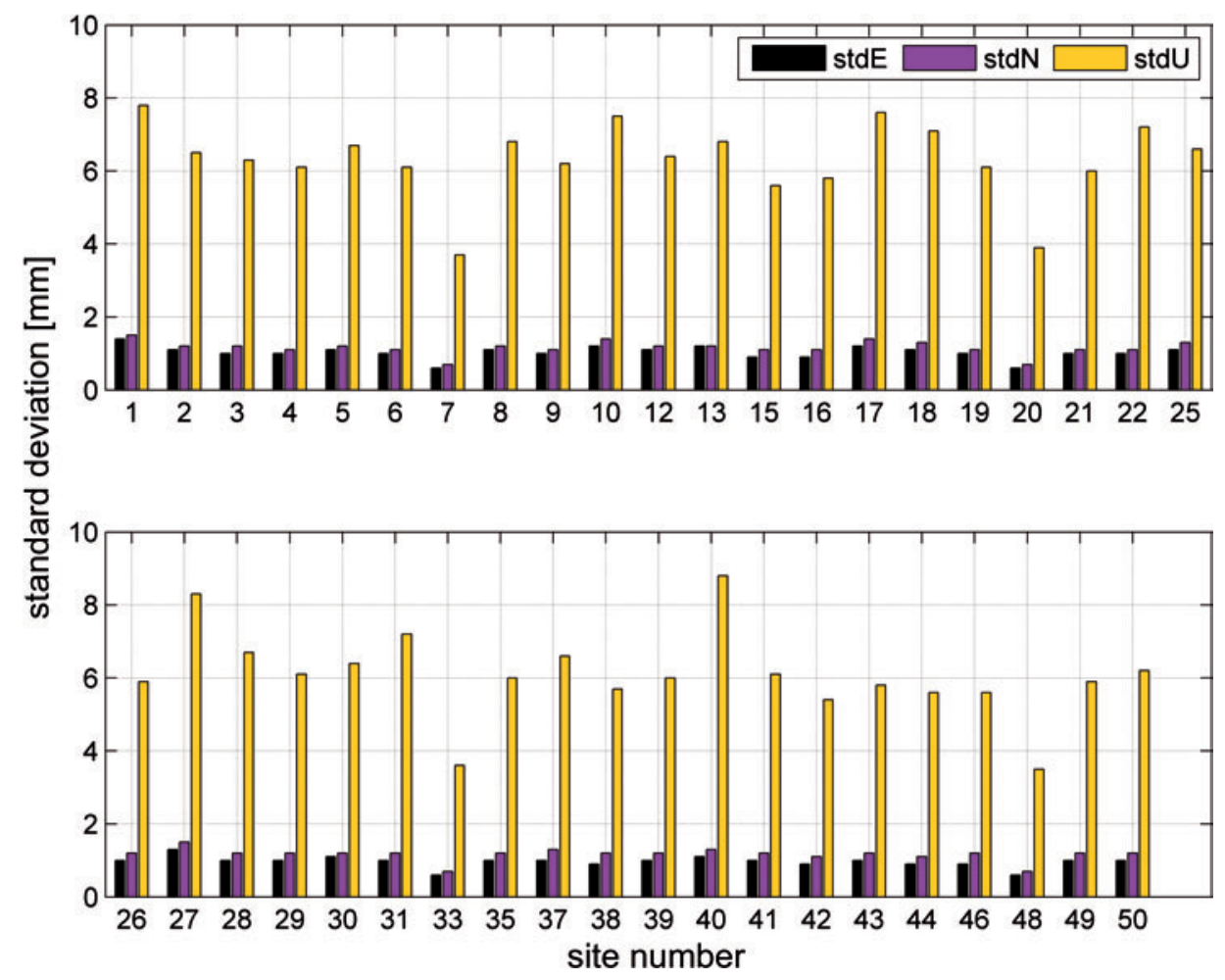

Figure 3: Standard deviations of the 'true' coordinates internally propagated from the Bernese processing. The means of the standard deviations are: $\mathrm{E}$ (ast) $1.0 \mathrm{~mm}$; $\mathrm{N}$ (orth) $1.2 \mathrm{~mm}$; $\mathrm{U}$ (p) $6.2 \mathrm{~mm}$.

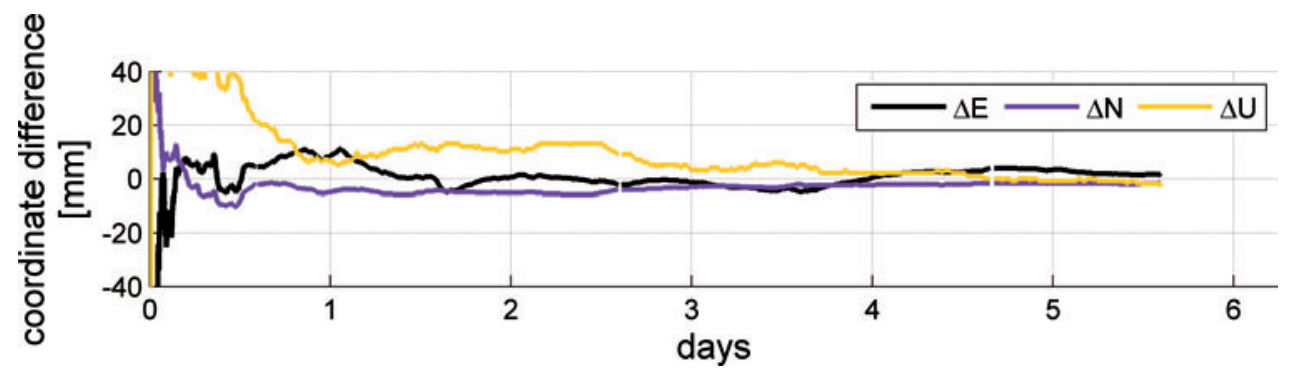

Figure 4: Coordinate differences ( 4 ) between CSRS PPP and the Bernese network solution versus observation time for site SZ41, the best solution in the horizontal component.

ITRF2000 coordinates compared with Hu's (2007) Bernese v5 solution, as follows.

\section{Results \& discussion}

\subsection{Analysis of the time behaviour of the PPP solution}

We first investigated the time behaviour of the PPP results in relation to the 'true' Bernese coordinates. The aim was to see how long it takes for the CSRS solutions to converge, and if a much longer observation time can really improve the coordinates (with respect to the 'true' coordinates) and their standard deviations (as delivered by the CSRS service). Unfortunately, however, the maximum observation duration accepted by CSRS is limited to seven days including products for day $n+1$ needed to process data beyond 23 hours, 55 minutes on day $n$. For this reason, the processed data in most cases covered an observation time of approximately six days, except for a small number of SWSZ sites that were observed for a shorter period (but most were observed for seven days).

This analysis of the time behaviour is exemplified for those stations that gave the best and worst PPP solutions in the horizontal component $(\mathrm{E}, \mathrm{N})$ and separately for the height component $(\mathrm{U})$. The coordinate differences $(\Delta)$ are the CSRS PPP solution minus the Bernese solution. The criterion to choose the best and worst solution in the horizontal was the magnitude of the horizontal displacement of the PPP solution from the Bernese solution (i.e., $\Delta_{\text {horizontal }}=\sqrt{\Delta \mathrm{E}^{2}+\Delta \mathrm{N}^{2}}$ ). The best PPP solution in the horizontal is at site SZ41 with $\Delta_{\text {horizontal }}=2.4 \mathrm{~mm}$ (Figure 4); the worst solution is at site SZ10 with $\Delta_{\text {horizontal }}=14.7 \mathrm{~mm}$ 


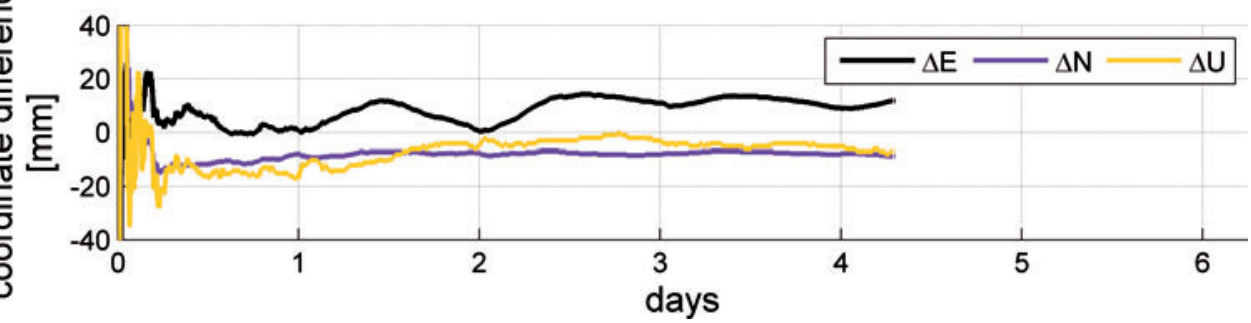

Figure 5: Coordinate differences $(\Delta)$ between CSRS PPP and the Bernese network solution versus observation time for site SZ10, the worst solution in the horizontal component. This is one of a small number of sites that was occupied for only four days.

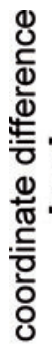

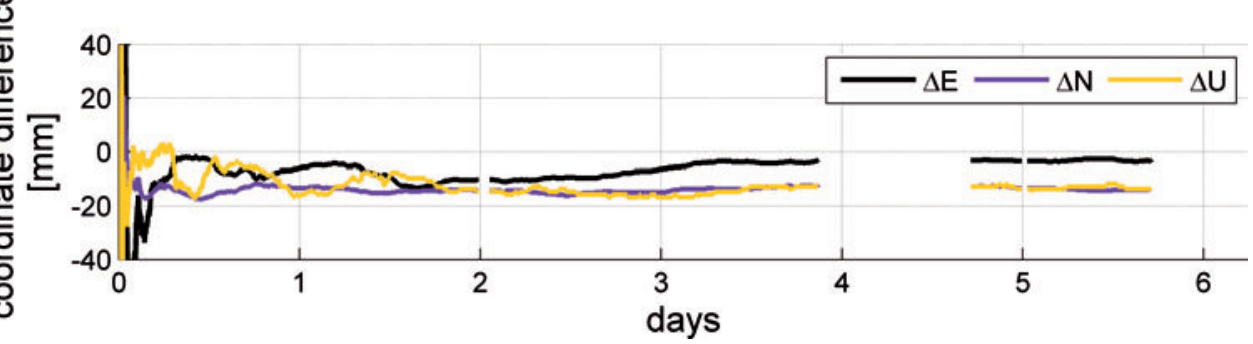

Figure 6: Coordinate differences ( $\triangle$ ) between CSRS PPP and the Bernese network solution versus observation time for site SZ08, the second-worst solution in the horizontal component. The solution is stable after the one-day data interruption.

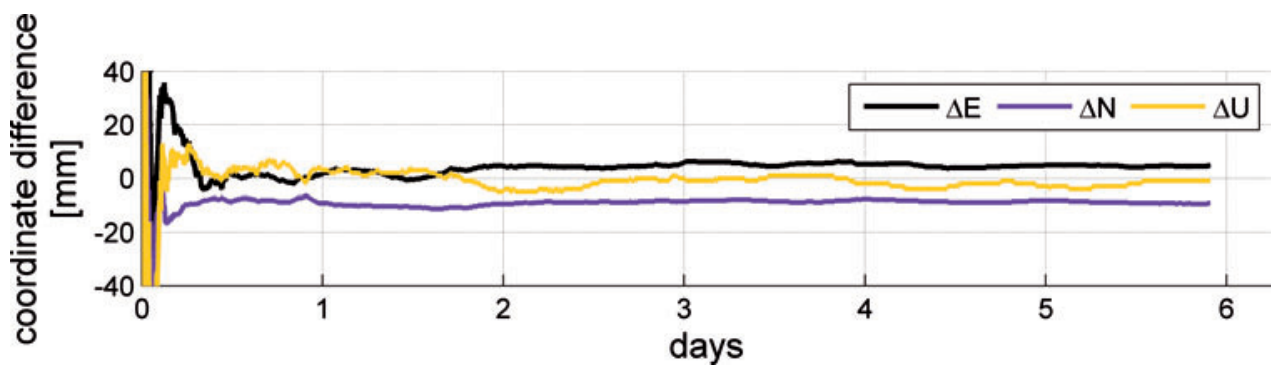

Figure 7: Coordinate differences $(\Delta)$ between CSRS PPP and the Bernese network solution versus observation time for site SZ30, the best solution in the vertical component.

(Figure 5). However, the observation time for SZ10 was only four days.

The second-worst CSRS solution in the horizontal was at site SZ08, where $\Delta_{\text {horizontal }}=14.3 \mathrm{~mm}$. This site has a break in the observations of almost one day (Figure 6). It is interesting to see that the CSRS solution remains quite consistent after this interruption, unlike the varying solution in the first day of occupation. This indicates that CSRS is able to handle data interruptions. For instance, the survey crew may lose power at the observation site, but if they are able to rectify the problem in a day, then the final CSRS solution may not be compromised (but see later). However, this will probably not be the case if the interruption occurs within the first one or two days.

The best CSRS solution for the vertical component (U) was achieved at site $\mathrm{SZ30}$ with $\Delta_{\text {vertical }}=$ $0.3 \mathrm{~mm}$ (Figure 7); the worst solution was at site SZ22 with $\Delta_{\text {vertical }}=28.5 \mathrm{~mm}$ (Figure 9). This of particular concern because the $\mathrm{U}$ solution is biased by $\sim 30 \mathrm{~cm}$ (Figure 9), but this is not reflected in the standard deviations delivered by CSRS (Figure 10), which are very similar to those delivered for the best U solution (Figure 8).

There is also a near-daily oscillation in the E component of the CSRS solution for site SZ22 (Figure 9), which occurs at other stations where there is a height bias. As such, there appears to be some correlation between the two. We therefore examined the CSRS reports and found that the carrier-phase residuals, station-clock offsets and the pseudo-range residuals all exhibit jumps at these problematic sites. Since this occurred for all receiver types, it suggests that there are problems with the site conditions (e.g., electrical interference or cycle slips on most satellites at the same time).

From Figures 4 to 10, the CSRS solutions tend to stabilise and approach the 'true' Bernese coordinates at the $\sim 20 \mathrm{~mm}$ level after 1-2 days of continuous occupation (except the problematic sites at SZ10 and SZ22). After this period, the time-varying behaviour of the coordinate differences becomes smoother, and 


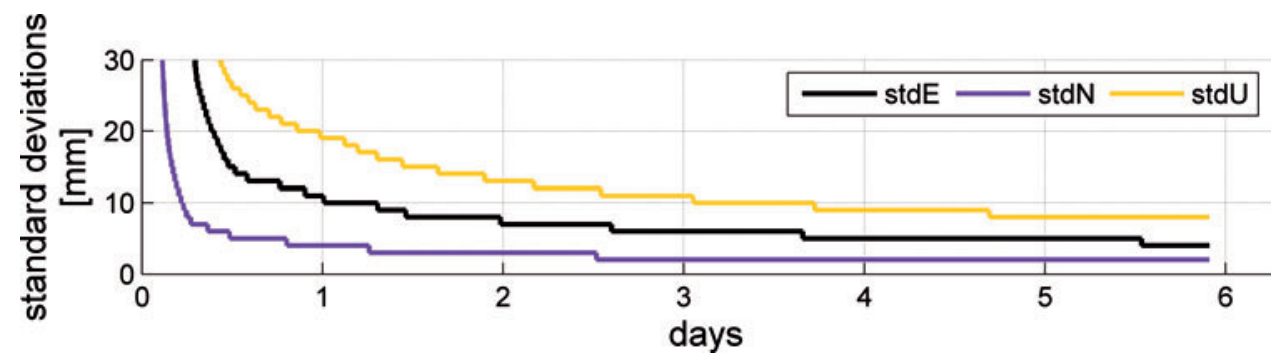

Figure 8: Standard deviations of the CSRS PPP solution versus the observation time for site SZ30.

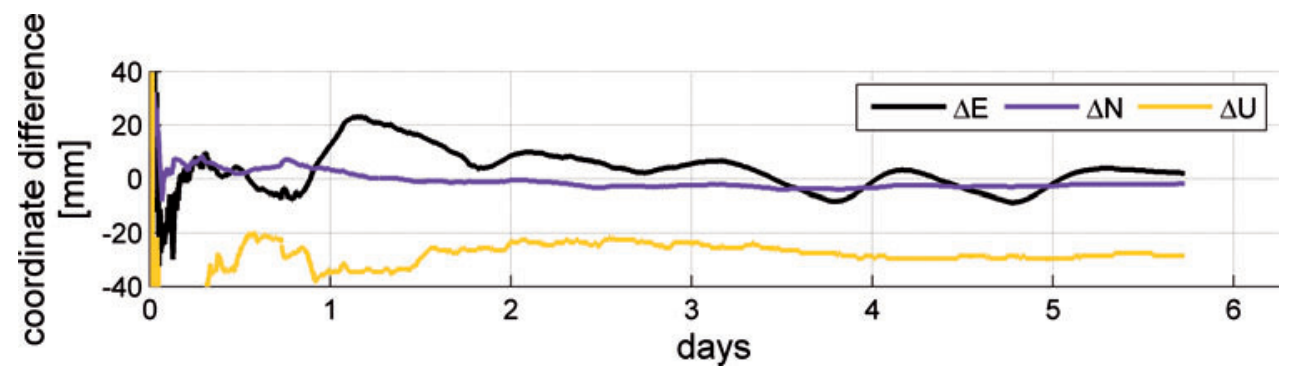

Figure 9: Coordinate differences ( 4 ) between CSRS PPP and the Bernese network solution versus observation time for site SZ22, the worst solution in the vertical component.

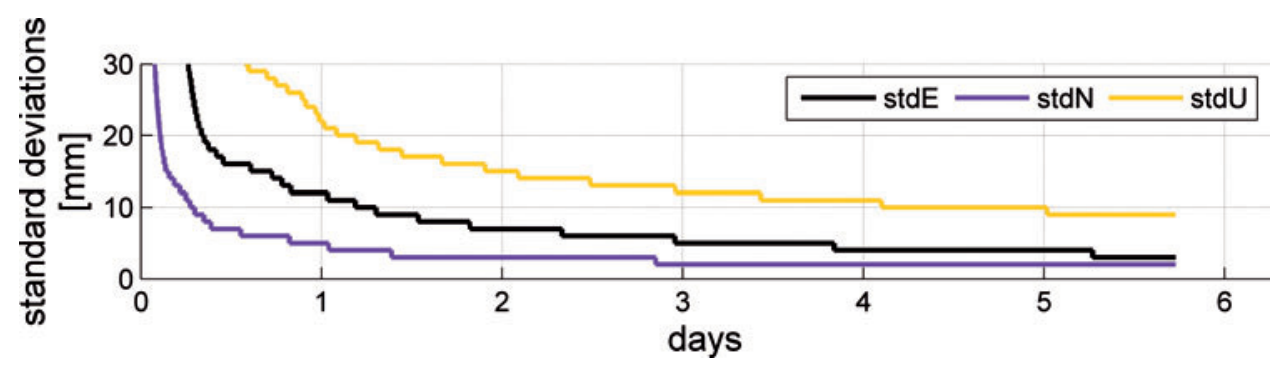

Figure 10: Standard deviations of the CSRS PPP solution versus the observation time for site SZ22.

the results only vary at the few-mm level. The standard deviation of the CSRS solutions improves over a six-day observation duration: on the fifth day, it decreases to about $50 \%$ of the value after two days' occupation. As such, at least two days of continuous occupation is recommended for any attempt to establish a geodetic survey control network with CSRS.

\subsection{Quality analysis of the geodetic control network achieved with PPP}

After computing the CSRS solutions for 46 of the sites in the SWSZ, some anomalous results were obtained (Figure 11). Sites SZ14, SZ24, SZ32, SZ34 and SZ45 show a significant and always-positive height bias from the 'true' Bernese-derived ellipsoidal height. The explanation is that the antenna type for these stations was not recognised by CSRS, hence no antenna PCO (phase centre offset) and PCV (phase centre variation) corrections were applied automatically in the data processing (cf. Hofmann-Wellenhof et al. 2008, pp. 148-154). As such, it is necessary to first ensure that the GPS antennas will be recognised by the online PPP processing service, otherwise significant $(\sim 10-15 \mathrm{~cm}$ in this case) height biases will result.

However, this antenna problem is relatively easy to ascertain before the PPP campaign starts, as follows. The field crew simply collects static GPS data with their instrumentation at a previously wellcoordinated test site, and then submits the RINEX data to their chosen PPP service. Comparing their results with the test site, in relation to the results presented in this paper, should indicate if there is an antenna-related problem with their instrumentation. Moreover, the reports generated by the online PPP service normally indicate if the GPS antenna type was recognised. If not, then the user must change to an antenna type that is recognised by the online PPP service. In this regard, it is important to remember that the cost of just one new GPS antenna is considerably less than the cost of establishing geodetic survey control with multiple instruments and field crews in the 'conventional' network-based way.

For the 2002 SWSZ data used here, the offending antenna types in Figure 11 were Ashtech 


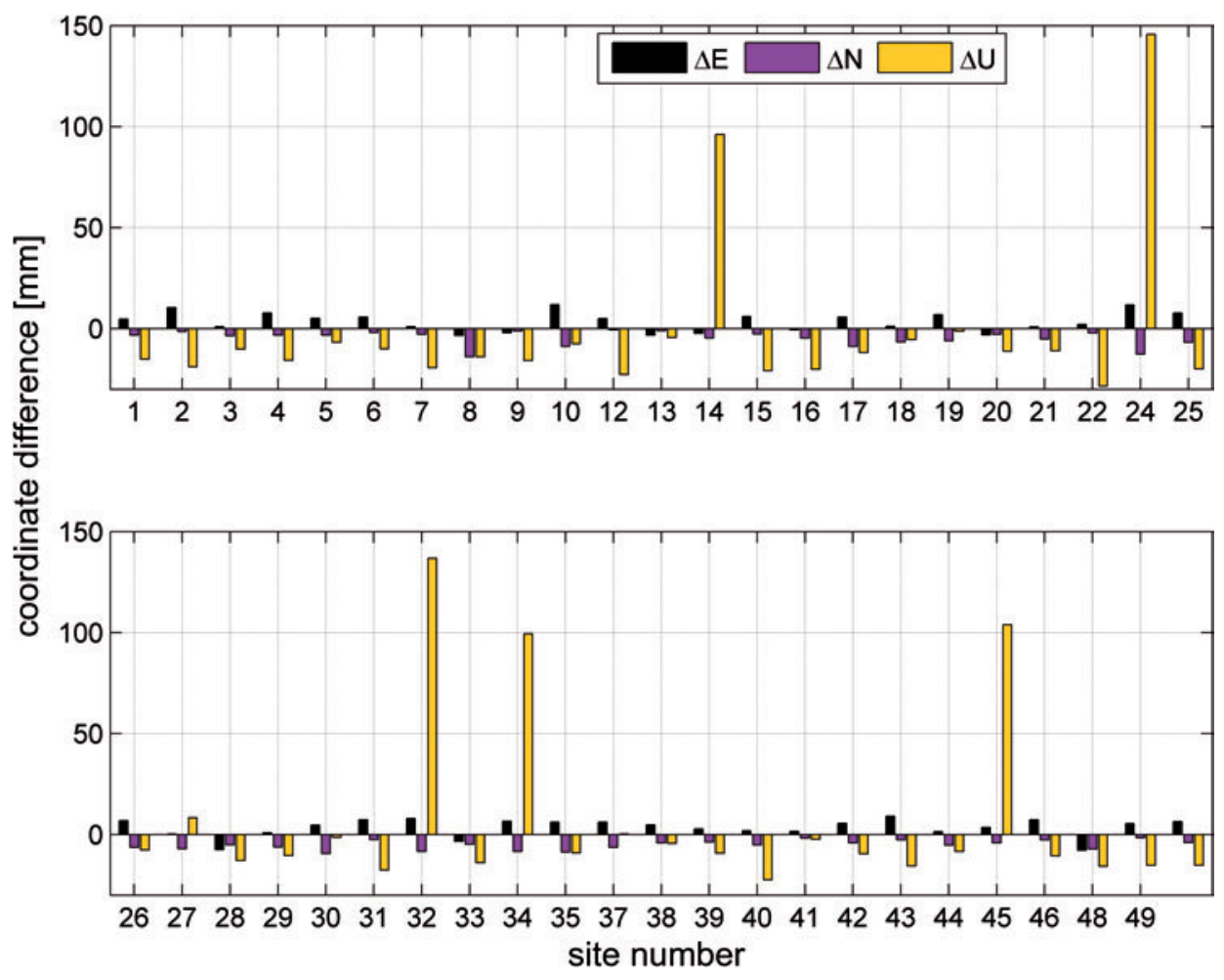

Figure 11: Coordinate differences $(\Delta)$ between CSRS PPP and the Bernese network solution; the case where PCOs and PCVs were not applied automatically at SZ14, SZ24, SZ32, SZ34 and SZ45 by CSRS.

ASH701975.01Agp for sites SZ14, SZ34 and SZ45 and Ashtech ASH701008.01B for sites SZ24 and SZ32. While these antennas are listed in the IGS ANTEX file, they had not been implemented in the CSRS PPP service at the time of this study. We therefore recommend that all IGS antenna types are embedded in the CSRS PPP service. Due to the insoluble problems with these two Ashtech antenna types, they were excluded from further investigation; the statistics of the differences for the remaining 41 sites are summarised in Table 1.

The results in Figure 13 and Table 1 (CSRS PPP minus Bernese) show that the differences in $\mathrm{E}$ are generally positive, whereas the differences in $\mathrm{N}$ and $\mathrm{U}$ are generally negative. The $\mathrm{N}$ differences are explained by the larger standard deviations for the Bernese solution, caused by the satellite constellation when us-

Table 1: Descriptive statistical summary of the coordinate differences $(\Delta)$ obtained with CSRS PPP and the Bernese network solution, excluding the five problematic Ashtech sites (units in $\mathrm{mm}$ ).

\begin{tabular}{llcr}
\hline & $\Delta \mathrm{E}$ & \multicolumn{1}{c}{$\Delta \mathrm{N}$} & \multicolumn{1}{c}{$\Delta \mathrm{U}$} \\
\hline $\min$ & 0.2 & -0.6 & 0.3 \\
& $(\mathrm{SZ27})$ & $(\mathrm{SZ12})$ & $(\mathrm{SZ30})$ \\
$\max$ & 11.8 & -13.9 & -28.5 \\
& $(\mathrm{SZ10})$ & $(\mathrm{SZ} 08)$ & $(\mathrm{SZ22})$ \\
mean & 3.3 & -4.8 & -11.5 \\
STD & 4.8 & 2.8 & 7.1 \\
\hline
\end{tabular}

ing fixed ambiguities (cf. Wang et al. 2002). The E differences are explained by the fact that the standard deviations of $\mathrm{E}$ are roughly twice as large as $\mathrm{N}$ in the PPP (shown and discussed next). The U differences are generally within $23 \mathrm{~mm}$ (excluding SZ22), which is consistent with expectation because GPS ellipsoidal height solutions are worse, irrespective of the post-processing technique used.

On average, the standard deviations of the CSRS solutions in Figure 13 are roughly two times larger for the vertical than the horizontal component. Contrary to the Bernese results (Figure 3), the average standard deviation of the $\mathrm{E}$ component is roughly twice as large as the $\mathrm{N}$ component, but which is very consistent $(\sim 2 \mathrm{~mm})$ for all 41 stations. This difference in precision is caused by error propagation in the PPP model, which depends on satellite geometry and the data processing model (i.e., unfixed ambiguities); see, e.g., Zumberge et al. (1997) and, Ge et al. (2007). As will be shown next, however, the differences are not statistically significant at the $99 \%$ confidence level for all but one station.

Finally, we compared the coordinate differences $(\Delta)$ for the 41 stations in relation to their internally propagated standard deviations reported from CSRS and Bernese to determine if they are statistically significantly different or the same. We used overlapping confidence intervals for the CSRS (Figure 13) and Bernese (Figure 3) solutions versus the coordinate differences (Figure 12) as an indicator of the signifi- 


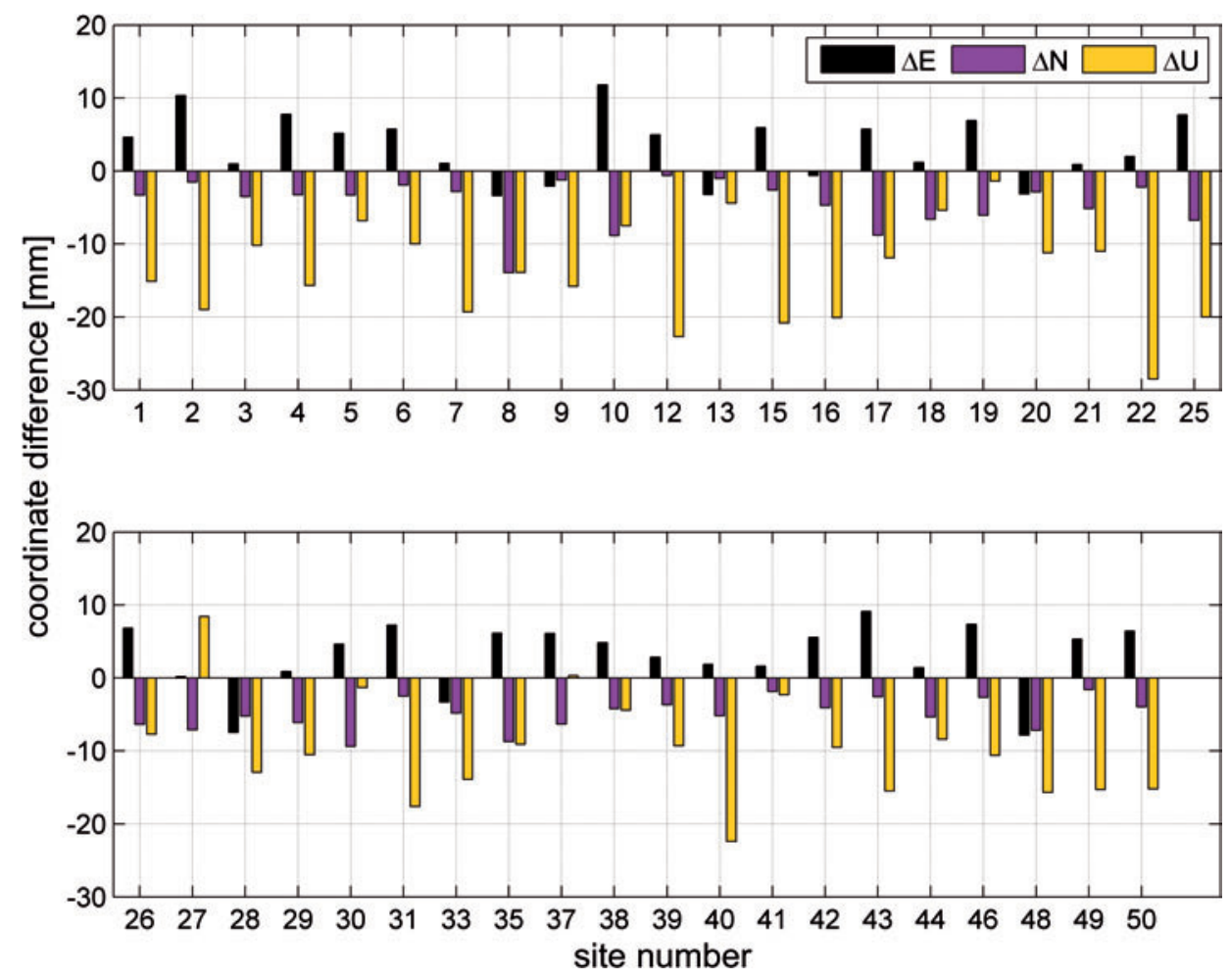

Figure 12: Coordinate differences $(\Delta)$ between CSRS PPP and the Bernese network solution, excluding stations where the PCOs and PCVs were not applied automatically.

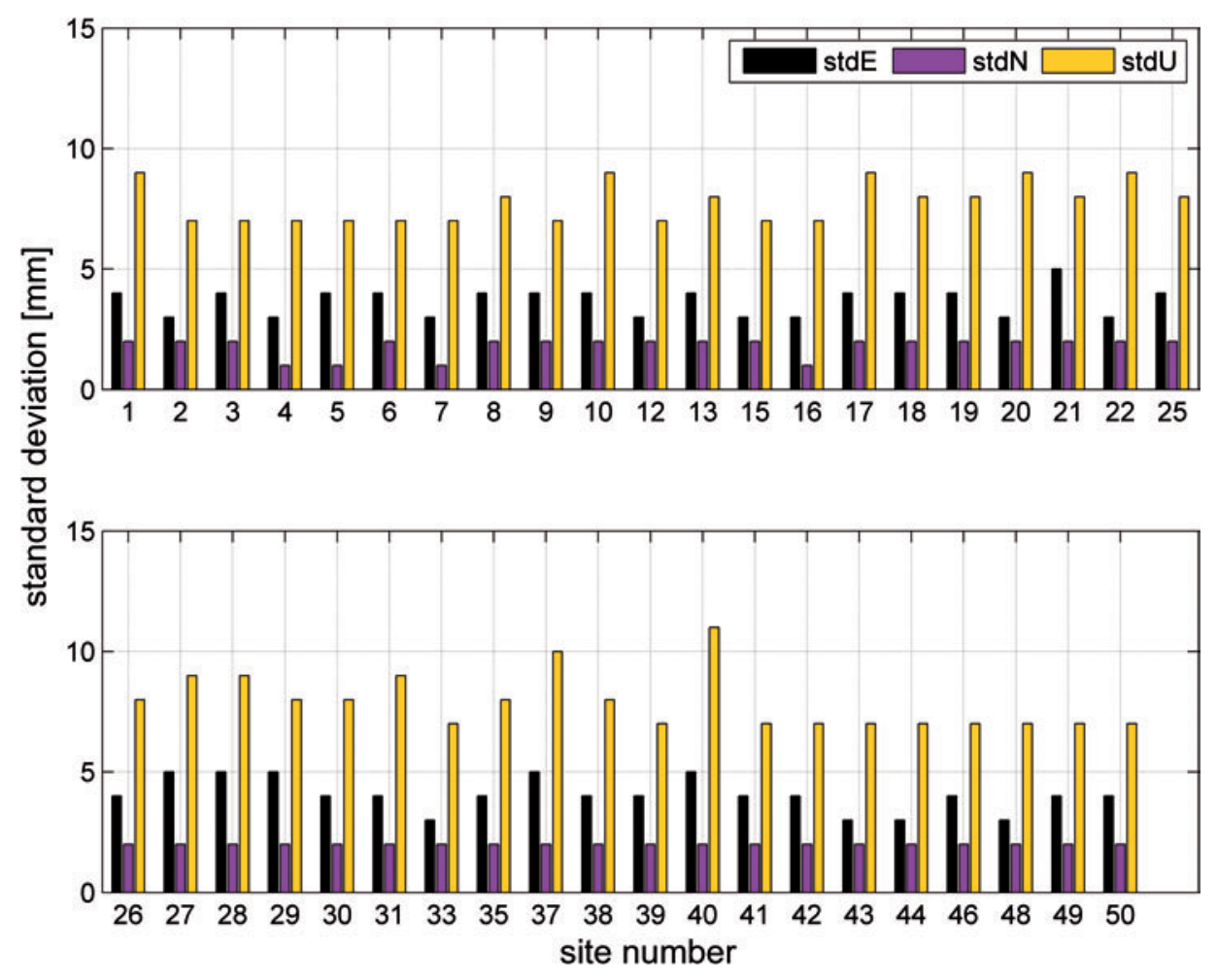

Figure 13: Standard deviations of the coordinates obtained with CSRS PPP, excluding stations where the PCOs and PCVs were not applied automatically. The means of the standard deviations are: $\mathrm{E}($ ast $) 3.9 \mathrm{~mm}$; $\mathrm{N}$ (orth) $1.9 \mathrm{~mm}$; $\mathrm{U}$ (p) $7.8 \mathrm{~mm}$. 


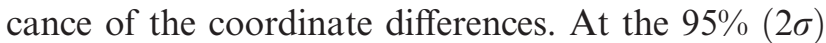
level for both solutions, the following sites showed statistically significant coordinate differences:

E: SZ02, SZ10, SZ43, SZ48

N: SZ08, SZ10, SZ16, SZ17, SZ18, SZ19, SZ25, SZ26, SZ27, SZ30, SZ35, SZ48

$\mathrm{U}$ : none

At the $99 \%(3 \sigma)$ level, the following showed statistically significant differences:

E: none

$\mathrm{N}: \mathrm{SZ08}$

$\mathrm{U}$ : none

Site SZ08 was the second-worst CSRS solution with a data gap (Figure 6). This contradicts the earlier observation that CSRS delivers a stable solution in the presence of a near-one-day data gap. As such, one should avoid data gaps, so if there is an equipment or power problem, the site should be re-observed for at least two days, or preferably more.

\section{Summary, conclusions \& recommendations}

We suggest that online PPP post-processing services could be used as an alternative to the 'conventional' network-based establishment of geodetic survey control networks. This approach reduces costs and logistics, where just one survey crew with just one geodetic-quality GPS receiver can establish a survey control network, albeit at a slightly lower accuracy than a full simultaneous network occupation. This is particularly attractive in remote regions or in developing countries, where geodetic survey control points might otherwise not exist.

To test this idea, we compared $3 \mathrm{D}$ coordinates from a moderate-sized ( $\sim 550 \mathrm{~km}$ by $\sim 440 \mathrm{~km})$ geodetic network of 46 points over part of south-western Western Australia processed with Bernese and with CSRS PPP. After rejection of five problematic sites, the PPP solutions agreed on average with the Bernese solutions to $3.3 \mathrm{~mm}$ in east, $4.8 \mathrm{~mm}$ in north and $11.8 \mathrm{~mm}$ in height. The average standard deviations of the Bernese solutions were $1.0 \mathrm{~mm}$ in east, $1.2 \mathrm{~mm}$ in north and $6.2 \mathrm{~mm}$ in height, whereas for CSRS they were $3.9 \mathrm{~mm}$ in east, $1.9 \mathrm{~mm}$ in north and $7.8 \mathrm{~mm}$ in height. At the $99 \%$ confidence level, only one CSRS solution (site SZ08) was significantly different to the Bernese solution in the north component, but this involved a near-one-day break in the observations.

Therefore, the suggested PPP-based approach does offer an alternative way to establish a geodetic survey control network, albeit at a slightly lower accuracy than the 'conventional' way. However, one has to consider a few other things in order to achieve the best results. Our analysis of the CSRS solution's time behaviour showed that at least two continuous days of observation is needed to achieve reliable re- sults. For most of the sites in the SWSZ test area, a PPP solution within $20 \mathrm{~mm}$ of the Bernese solution was obtained after two days of observation. However, a continuous observation duration as long as possible is recommended, but which is presently limited to six days by CSRS PPP.

A crucial consideration when using PPP is the GPS antennas. It was shown that an antenna not recognised by the PPP service causes significant errors due to the omission of PCO and PCV corrections. Consequently, it is essential to only use antennas that will be recognised by the PPP service chosen, and, moreover, to test those antennas in advance at well-known control points.

When considering these two things, i.e., a reasonable observation duration and recognised antenna types, $\mathrm{N}$ and $\mathrm{E}$ coordinates within $10 \mathrm{~mm}$ of the 'true' horizontal coordinates and a height (U) within $20 \mathrm{~mm}$ of the 'true' height can be expected, making this PPP-based approach to establishing a geodetic survey control network an attractive alternative to the conventional network-based approach, notably in remote areas or developing countries. Moreover, the PPP-based approach significantly reduces the equipment and personnel costs, pre-planning and logistics compared to 'conventional' GPS-network-based approaches.

\section{Acknowledgements}

We would like to thank Dr Guorong Hu of Geoscience Australia for providing the Bernese v5 solution for the 2002 SWSZ network. We would particularly like to thank Prof L. Wanninger and the other anonymous reviewer, who pointed out some key issues of clarification to us; thank you. WEF is funded by Australian Research Council grant DP0663020. This is The Institute for Geoscience Research publication number 119.

\section{References}

Altamimi, Z., Sillard, P. and Boucher, C., ITRF2000: A new release of the International Terrestrial Reference Frame for Earth science applications, J Geophys Res 107:B10 (2002) 2214.

Bock, Y., Abbot, R. I., Counselman, C. C., Gourevitch, S. A. and King, R. W., Establishment of three-dimensional geodetic control by interferometry with the Global Positioning System, J Geophys Res 90: B9 (1985), 7689-7703.

Cai, C. and Gao, Y., Precise point positioning using combined GPS and GLONASS observations, J GPS 6:1 (2007), 13-22.

Dawson, J., South West Seismic Zone 2002: GPS analysis, Unpublished Report, Geoscience Australia, Canberra, 2002.

Dentith, M. C. and Featherstone, W. E., Controls on intra-plate seismicity in southwestern Australia, Tectonophysics 376:3-4 (2003), $167-184$.

Featherstone, W. E. and Dent, V., Transfer of vertical geodetic control using only one GPS receiver: a case study, Australian Surv 47:1 (2002), 31-37.

Featherstone, W. E., Penna, N. T., Leonard, M., Clarke, D., Dawson, J., Dentith, M. C., Darby, D. and McCarthy, R., GPS-geodetic deformation monitoring of the south-west seismic zone of Western 
Australia: review, description of methodology and results from epoch-one, J Royal Soc Western Australia 87:1 (2004), 1-9.

Ge, M., Gendt, G., Rothacher, M., Shi, C. and Liu, J., Resolution of GPS carrier-phase ambiguities in Precise Point Positioning (PPP) with daily observations, J Geodesy (2007), DOI 10.1007/s00190007-0187-4, Erratum in 10.1007/s00190-007-0208-3.

Ghoddousi-Fard, R. and Dare, P., Online GPS processing services: an initial study, GPS Solut 10:1 (2005), 12-20.

$\mathrm{Hu}$, G., South West Seismic Zone: GPS analysis, Unpublished Report, Geoscience Australia, Canberra, 2007.

Hugentobler, U., Dach, R., Fridez, P. and Meindl, M. (eds), Bernese GPS software, version 5.0, Astronomical Institute, University of Berne, 2006.

Kouba, J. and Héroux, P., Precise point positioning using IGS orbit and clock products, GPS Solut 5:2 (2001), 12-28.

Moore, A. M. and Neilan, R. E., The International GPS Service tracking network: enabling diverse studies and projects through international cooperation, J Geodyn 40:4-5 (2005), 461-469.

Stewart, M. P., Houghton, H. and Ding, X. L., The STATEFIX west Australian GPS network, in Brunner, F. (ed) Advances in Positioning and Reference Frames, 1997, Springer, Berlin Heidelberg New York, 155-160.

Wang, J., Iz, B. H. and Lu, C., Dependency of GPS positioning precision on station location, GPS Solut 6:1-2 (2002), 91-95.

Zumberge, J. F., Heflin, M. B., Jefferson, D. C., Watkins, M. M. and Webb, F. H., Precise point positioning for the efficient and robust analysis of GPS data from large networks, J Geophys Res 102:B3 (1997), 5005-5017.

Received: Mar 24, 2008

\section{Author information}

\section{R. Ebner}

Institute of Navigation and Satellite Geodesy

University of Technology Graz

Steyrergasse 30

8010 Graz, Austria

E-mail: ebnr@sbox.tugraz.at

W. E. Featherstone

Western Australian Centre for Geodesy \&

The Institute for Geoscience Research

Curtin University of Technology

GPO Box U1987

Perth WA 6845, Australia

Email: W.Featherstone@curtin.edu.au

Tel: +61 89266 2734; Fax: +61 892662703 